\title{
Editorial
}

Hurrah! Law librarians or rather "Legal Information Managers", "Knowledge Managers" and "Directors of Information Services", have at last received a good press from no less than our old friends Sweet \& Maxwell, with subsequent coverage in The Times. It seems that they have conducted a survey of library and information services within the top 100 law firms and have discovered that the position and prospects of law librarians have improved greatly over the last few years and particularly since the advent of Knowledge Management, with over twenty per cent of us now reporting either directly to the Managing Partner or sitting on the management board. This is very good news for us professionally and makes a welcome change from the not too distant past when redundancies were the order of the day.

There are quite large sums of money being paid to the holders of these positions and there is no doubt that their jobs now encompass a great deal more than simply applying their traditional information skills. Some of them manage very large global teams - one well-known occupant of such a position manages over 70 staff world-wide. They are also frequently involved in very high budget projects such as managing the installation of firm-wide knowledge portals or implementing knowledge management systems and software. They need to have excellent negotiation skills to deal with sometimes difficult IT departments and a variety of outside suppliers. Some library budgets are now stratospheric in size and there is all that negiotiation to do with the vendors. Our next issue will carry a series of case studies on managing multi-site libraries and we are also hoping to hear about the experiences of one of our more seasoned head of global library services.

It is very good news for the legal information profession that our members are moving on to such responsible positions and hopefully the image of the libarian in bun and glasses will be banished forever! This leads me on nicely to the first part of this issue which covers a selection of Conference Papers, including the final very interesting and stimulating paper presented by Adrian Dale entitled Back to the Future which reiterates the findings of the Sweet \& Maxwell survey that we are capable of rising to dizzy heights in the Information Society.

Another aspect of our work which is gaining increasing prominence is that of training. In all types of law library we are being called upon more and more to be involved in training students and lawyers how to use databases as well as the traditional paper sources. Sharon Markless gave a very interesting paper to the Conference on the skills we need to develop to be able to deliver effective training.

One session of the Conference was devoted to challenges facing the various sectors in which we work and two of the resultant papers appear here - Catherine Hearn tells us about life in a large provincial firm which has expanded very rapidly recently and also covers a wide area of practice and Valerie Stevenson writes about her work in a large university library in this age of financial hassle in the academic sector.

Marianne Barber has provided us with a very useful account of the virtual learning environment at the College of Law and the article is particularly timely for those of us outside the academic sector who may not have much experience of VLEs.

We are continuing our knowledge management theme from the Summer issue with articles about the KM systems offered by LexisNexis and West. We do not regard these articles as advertorials for the products described, as we specially commissioned them and both the key vendors agreed to write for us. The systems described are currently only available in the US but no doubt they will shortly appear here so forewarned is forearmed.

Amanda McKenzie writes about how she manages to provide knowledge management services at Olswangs by working closely with the professional support lawyers. This is an area that can easily cause friction between the information services departments and PSLs in large law firms and needs to be handled sensitively. Amanda supplies a few pointers on how to avoid difficulties.

In our current topics, Marion Huckle has provided a comprehensive overview of CILIP's new Framework of Qualifications which is still being worked upon but the final version is nearly there and the changes should be of interest to us all. The new arrangements are due to be rolled out in April 2005.

We have two contributions from overseas law librarians in this issue. Cynthia Fellows, who is a visiting fellow at the Institute of Advanced Legal Studies, has written a fascinating account of the development of the State of Alaska with lots of amazing old photos. It is astonishing to realise that it only achieved statehood as the 49th State in 1959. She also tells about her experiences there as a law librarian.

Conrad van Laer and his colleagues from the Netherlands visited four libraries in this country earlier this year and he recounts his experiences for us. We are hoping in the future to increase our coverage of overseas legal information issues and are starting a regular column in our Spring issue next year when John Eaton will be our first contributor with his letter from Canada.

This issue also contains the index for Volumes I-4 of Legal Information Management and we are very grateful to Mary Jane Steer for producing it for us. 


\title{
Adrian Dale
}

We are approaching the end of our first year with our new publishers, Cambridge University Press, and we will be reviewing with them the events of the year shortly, to try and identify areas of concern, but overall it has been a very good year as far as editorial support has been concerned. Our publishing editor, Ella Colvin, has been a tower of strength and astonishingly efficient on our behalf.

Another new development in 2005 is that we are planning to introduce a refereed section in a bid to publish some slightly more rigorous, academic articles in the journal. We will shortly be approaching people to ask them whether they will be prepared to join our panel of referees and we will be drawing up guidelines for the refereeing process. This does not mean that the journal has lost sight of its mission statement or its aims and objects as we will continue to focus on short practical articles - we will only carry one refereed article in each issue but we would very much like to attract contributions from the academic sector.
We have had problems over the last year in receiving too much material for the journal which means that we have been holding articles over from one issue to another. This is not a satisfactory situation for anyone as it is always terrible to have to tell someone who has slaved over a hot computer to hit a deadline that his article will be held over and it is equally frustrating for the poor author. For this reason we will not be publishing all the Conference 2004 papers and nor will we be publishing all the papers from the Weekend Study Conference. We will also be moving some material from LIM to the Newsletter but final decisions have not yet been taken on exactly what this will be.

As the end of another LIM year approaches I would like to thank all the members of the Editorial Board for their continued support, all the BIALL members who have given up their valuable time to write for the journal and Gillian Sands, Sam Weston-Smith, Jo Tomlinson and Lindsey Caffin for their regular Current Awareness and IT columns.

Christine Miskin

\section{Back to the Future}

\author{
Paper presented to the 35th BIALL Annual Study Conference in Edinburgh, June \\ 2004 by Adrian Dale.
}

\section{Introduction}

Let 2004 be a turning point for the library and information profession. A glorious year for it to reaffirm its role in the corporate world - reclaiming its future by taking back many of the roles and responsibilities that it has given up to other professions over the last few years.

The opportunities of knowledge management are manifold. And whilst they might appear to offer something new for the profession, in this paper we argue that they aren't really new opportunities. Many of these new roles are actually the birth right of librarians and information professionals and something they should never have let

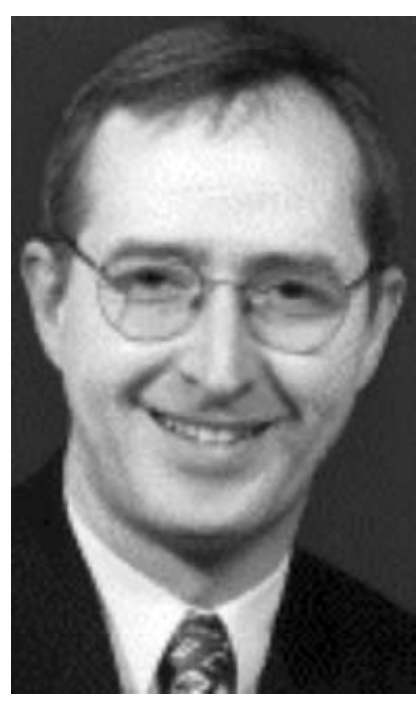

Adrian Dale this ground - many of them doing a creditable job in the areas we trained long and hard for. So some fancy footwork will be needed and dare I say it some aggression. Yes our profession needs to learn to fight. So we'll explore the principles of corporate judo - a set of techniques that will out smart your competition - pushing them back as you reclaim your future.

\section{Knowledge management - new concepts or old}

The debate about the validity of knowledge management as a concept has raged across the library world. For some librarians it is But they won't get back their future without a fight. There are a whole range of professions now claiming an exciting new concept that gives renewed purpose and legitimacy to their work in the corporate world. 